\title{
Turismo rural em faxinais: uma alternativa não agrícola de desenvolvimento local e de fixação do homem no campo
}

Rural tourism in faxinais: a non agricultural alternative for local development and fixing man in the field

Turismo rural en faxinales: una alternativa no agrícola de desarrollo local y de fijación del hombre en el campo

Rosiane Mikuska ${ }^{1}$ Ronaldo Ferreira Maganhotto²

${ }^{1}$ Mestre em Desenvolvimento Comunitário e graduada em Ciências Contábeis pela Universidade Estadual do Centro-Oeste (UNICENTRO), Guarapuava, PR. E-mail: rosianemikuska@hotmail.com, Orcid: http://orcid.org/0000-0002-1129-9461

${ }^{2}$ Doutor em Geografia pela Universidade Federal do Paraná. Professor do Programa de Pós-Graduação Interdisciplinar em Desenvolvimento Comunitário (PPGDC), Universidade Estadual do Centro-Oeste (UNICENTRO), Guarapuava,PR. E-mail: ronaldomaganhotto@gmail.com, Orcid: http://orcid.org/0000-0003-0659-1481 
Resumo: As atividades rurais não agrícolas vêm se tornando mais comuns no meio rural brasileiro, dentre as quais se destaca o turismo. O presente artigo apresenta um estudo bibliográfico acerca do turismo em terras de faxinais no estado do Paraná e tem como objetivo apresentar as possibilidades e limitações da implementação da atividade turística nas terras de Faxinal, a partir das publicações com a referida temática. Nesse contexto, a presente pesquisa configura-se como de caráter qualitativo, tendo como técnica de pesquisa o levantamento e análise bibliométrica. Verificou-se a escassez de pesquisas envolvendo turismo em áreas faxinalenses. Dos estudos encontrados na base Google Acadêmico, três abordam o turismo rural em faxinais de Prudentópolis e de Mallet, municípios que apresentam maior incidência de faxinais na região. Ressalta-se a inexistência de estudos sobre o tema elencado em bases como Scielo e Scopus. Quanto às possibilidades, verificou-se que os aspectos paisagísticos (naturais e rurais) e culturais (religiosidade e gastronomia) configuram-se como sendo elementos peculiares às áreas de Faxinal. No entanto o acesso (estrada e sinalização), a adequação da propriedade e necessidade de investimentos, assim como o entendimento do pequeno agricultor quanto à prestação de serviço, reportam-se aos desafios a serem superados para implementação da atividade turística e de lazer como alternativa não agrícola no meio rural.

Palavras-chave: faxinal; Paraná; turismo rural.

\begin{abstract}
Non-agricultural rural activities are becoming more common in the Brazilian countryside, among which tourism stands out. This article presents a bibliographical study about tourism in faxinal lands in the state of Paraná and aims to present the possibilities and limitations of the implementation of tourism in the lands of Faxinal, based on the publications with this theme. In this context, the present research configures itself as being of qualitative character, having as survey technique the survey and bibliometric analysis. There was a lack of research involving tourism in faxinalenses areas. Of the studies found in the Google Scholar base, three approach rural tourism in faxes of Prudentópolis and Mallet, municipalities that present a higher incidence of faxinais in the region. It should be emphasized that there are no studies on the theme listed in such databases as Scielo and Scopus. As for the possibilities, it was verified that the landscape aspects (natural and rural) and cultural (religiosity and gastronomy) are like elements peculiar to the areas of Faxinal. However, access (road and signage), the adequacy of the property and the need for investments, as well as the understanding of the small farmer regarding the provision of services, relate to the challenges to be overcome for the implementation of tourism and leisure activity as non-agricultural alternative in rural areas.
\end{abstract}

Keywords: faxinal; Paraná; rural tourism.

Resumen: Las actividades rurales no agrícolas se han vuelto más comunes en el medio rural brasileño, entre las que destaca el turismo. El presente artículo presenta un estudio bibliográfico acerca del turismo en tierras de faxinas en el estado de Paraná y tiene como objetivo presentar las posibilidades y limitaciones de la implementación de la actividad turística en las tierras de Faxinal a partir de las publicaciones con la referida temática. En este contexto, la presente investigación se configura como de carácter cualitativo, teniendo como técnica de investigación el levantamiento y análisis bibliométrico. Se verificó la escasez de investigaciones que involucra turismo en áreas faxinalenses. De los estudios encontrados en la base Google Académico, tres abordan el turismo rural en faxistas de Prudentópolis y de Mallet, municipios que presentan mayor incidencia de faxistas en la región. Se resalta, la inexistencia de estudios sobre el tema enmarcado en bases como Scielo y Scopus. En cuanto a las posibilidades, se verificó que los aspectos paisajísticos (naturales y rurales) y culturales (religiosidad y gastronomía) se configuran como elementos peculiares a las áreas de Faxinal. Sin embargo, el acceso (camino y señalización), la adecuación de la propiedad y la necesidad de inversiones, así como el entendimiento del pequeño agricultor en cuanto a la prestación de servicio, se refieren a los desafíos a ser superados para la implementación de la actividad turística y de ocio, alternativa no agrícola en el medio rural.

Palabras clave: faxinal; Paraná; turismo rural. 
Turismo rural em faxinais: uma alternativa não agrícola de desenvolvimento local e de fixação do homem no campo

\section{INTRODUÇÃO}

O turismo é uma atividade que sofre mudanças e inovações constantes, em função de novas exigências da demanda e da contínua e acirrada competitividade dos mercados. Tais alterações têm se apresentado como fator responsável por transformações no ramo turístico, empresas têm se adequado à demanda de públicos específicos, que têm deixado de lado a correria das cidades e optado por ambientes mais tranquilos.

O comportamento do turista vem mudando, surgindo novas motivações de viagens e expectativas que precisam ser atendidas. Em um mundo globalizado, onde o diferencial é peça chave e adquire importância a cada dia, os turistas passam a exigir, cada vez mais, roteiros turísticos que se adaptem às suas necessidades, condições financeiras, seus desejos e preferências.

O crescimento dos espaços urbanos aliados à expansão do agronegócio são alguns dos fatores responsáveis pela intensificação da degradação de áreas naturais; em contrapartida, a busca por elas tem aumentado, dando lugar às novas formas de turismo, proporcionando a realização de atividades junto à natureza.

Isso influi diretamente no fortalecimento de novos seguimentos de turismo, como por exemplo, o Turismo Rural, uma atividade relativamente nova em solo brasileiro, que vem com a proposta de melhora nos rendimentos dos proprietários rurais e maior valorização da ruralidade e do contato com a natureza.

Seus primeiros indícios no Brasil datam da década de 1980, mais especificamente na fazenda Pedra Branca, em Santa Catarina, no município de Lages, propriedade que oferecia uma proposta de pernoite e vivência de um dia de vida no campo aos visitantes. As iniciativas se expandiram por toda a região Sul, e hoje temos dados de que a atividade é desenvolvida em todo o país.

Atualmente é considerada uma atividade com crescimento acelerado no mundo, estimando-se que tal crescimento manter-se-á pelos próximos 15 anos. Apesar de ser considerado um conceito novo para o Brasil, esse tipo de turismo já vem sendo amplamente praticado, principalmente em países europeus. 
Muito embora essa tendência de crescimento seja animadora, ela desperta certa preocupação quanto à forma como esse desenvolvimento acontecerá, pois, de modo geral, as áreas mais frágeis e que necessitam de preservação estão justamente nos ambientes rurais.

O turismo no meio rural constitui-se numa forma de valorização do território, pois, ao mesmo tempo em que depende da gestão do espaço rural para o seu sucesso, contribui para a proteção do meio ambiente e para a conservação do patrimônio natural, histórico e cultural do meio rural.

O Paraná é um dos estados da Federação Brasileira que apresenta grande potencial turístico, tanto em áreas urbanas, quanto em rurais. Em seu interior, embora em número reduzido, existe um sistema único no mundo que apresenta características culturais bem marcantes, contribuindo para a fixação do homem do campo e para a manutenção da paisagem formada pela floresta de araucária, um bioma em extinção - O Sistema Faxinal, que, devido a seu caráter de preservação, apresenta áreas naturais pouco exploradas.

O faxinal é um sistema comumente encontrado no estado do Paraná, mais especificadamente na região Centro-Sul, organizado através de três elementos: o criadouro comunitário (área de uso comum de terras), as terras de plantar de uso privado e as cercas e/ou valos, separando os dois primeiros espaços. Essas comunidades tradicionais possuem suas bases calcadas em atividades que utilizam a produção animal como meio de tração e também para consumo próprio, e a produção agrícola, como meio de subsistência.

O turismo rural se apresenta, hoje, como uma alternativa para áreas tradicionais do campo brasileiro, como fonte de renda extra e alternativa na minimização do êxodo rural, fixando o homem na sua terra natal. Porém há de se ressaltar a necessidade de uma avaliação e discussão sobre os impactos que o turismo pode gerar nessas comunidades, de maneira a potencializar os benefícios para esse meio sem descaracterizá-lo. Portanto o desenvolvimento da atividade turística em comunidades tradicionais de forma geral, e nos Faxinais, no caso dessa discussão, deve levar em consideração o choque cultural que esta possibilitará.

Por meio deste estudo, busca-se apresentar a atividade turística como alternativa válida para impulsionar o desenvolvimento das comunidades faxinalenses, minimizando o êxodo rural e incentivando a agricultura familiar. 
Turismo rural em faxinais: uma alternativa não agrícola de desenvolvimento local e de fixação do homem no campo

\section{METODOLOGIA}

A Bibliometria é uma técnica de pesquisa que emerge no inicio do século XX como uma resposta à necessidade de estudos e avaliações da comunicação e da produção científica. Considerado um dos maiores e de maior contribuição em estudos bibliométricos, Solla Price enaltece a importância dessa abordagem dizendo que:

Deixando de lado os julgamentos de valor, parece clara a importância de se dispor de uma distribuição que nos informe sobre o número de autores, trabalhos, países ou revistas que existem em cada categoria de produtividade, utilidade ou o que mais desejarmos saber. (PRICE, 1976, p. 39).

Esse método de pesquisa apresenta como principal característica a elaboração de índices de produção do conhecimento científico. Sua análise em pesquisas científicas se pauta em investigar o comportamento do conhecimento e da literatura enquanto parte dos processos de comunicação.

Para a realização da pesquisa aqui relatada, elegeu-se como fontes as bases de dados: Google, Google Acadêmico, Scielo e SciVerse Scopus, referida apenas como Scopus, plataforma lançada em 2004 pela Elsevier. A escolha desta última base deu-se principalmente por se tratar

[...] da maior base de resumos e referências bibliográficas de literatura científica revisada por pares, com mais de 18.000 títulos de 5.000 editoras internacionais. A Scopus permite uma visão multidisciplinar da ciência e integra todas as fontes relevantes para a pesquisa básica, aplicada e inovação tecnológica através de patentes, fontes da web de conteúdo científico, periódicos de acesso aberto, memórias de congressos e conferências. É atualizada diariamente e contém os Articles in Press de mais de 3.000 revistas. (ELSEVIER, 2010).

Os dados dos artigos selecionados foram salvos em uma planilha de dados do Microsoft Excel, para uma melhor organização e visualização das informações.

Trata-se de uma pesquisa qualitativa e levantamento e com cunho bibliométrico, permeada por reflexões sobre as atividades turísticas no meio rural, especialmente em comunidades paranaenses que ainda mantêm o Sistema Faxinal. Foram utilizados como fontes de informações para 
a coleta de dados, livros e periódicos nacionais encontrados junto às bases de pesquisas apresentadas no Quadro 1.

Quadro 1- Pesquisas sobre turismo em faxinal e as suas respectivas bases.

\begin{tabular}{|l|l|l|c|}
\hline \multicolumn{1}{|c|}{ Título } & \multicolumn{1}{|c|}{ Autor (es) } & \multicolumn{1}{|c|}{ Base } & Ano \\
\hline $\begin{array}{l}\text { Diagnóstico da Potencialidade Turís- } \\
\text { tica da Propriedade Faxinal Dérevo, } \\
\text { na Comunidade Papanduva de Baixo } \\
\text { do Município de Prudentópolis/PR. }\end{array}$ & Mozart Martins Silva & Google & 2012 \\
\hline $\begin{array}{l}\text { Os faxinais do município de Pruden- } \\
\text { tópolis-PR: potencialidade e pers- } \\
\text { pectivas para o turismo rural. }\end{array}$ & $\begin{array}{l}\text { Dircéia Antunes de } \\
\text { Oliveira }\end{array}$ & $\begin{array}{l}\text { Google } \\
\text { Acadêmico }\end{array}$ & 2008 \\
\hline $\begin{array}{l}\text { O novo rural em comunidades tradi- } \\
\text { cionais faxinalenses: reflexões sobre } \\
\text { a proposta de turismo para os faxi- } \\
\text { nais do município de Mallet - Paraná } \\
\text { - Brasil. }\end{array}$ & $\begin{array}{l}\text { Rodrigo Rocha } \\
\text { Monteiro }\end{array}$ & $\begin{array}{l}\text { Google } \\
\text { Acadêmico }\end{array}$ & 2010 \\
\hline $\begin{array}{l}\text { Turismo comunitário: reflexões sobre } \\
\text { os faxinais do município de Pruden- } \\
\text { tópolis - Paraná }\end{array}$ & $\begin{array}{l}\text { Pedro Henrique } \\
\text { Sanches Lemes }\end{array}$ & $\begin{array}{l}\text { Google } \\
\text { Acadêmico }\end{array}$ & 2010 \\
\hline $\begin{array}{l}\text { O turismo em comunidades tradi- } \\
\text { cionais faxinalenses: uma discussão } \\
\text { sobre as transformações recentes no } \\
\text { campo brasileiro e seus reflexos para } \\
\text { as comunidades tradicionais }\end{array}$ & $\begin{array}{l}\text { Rodrigo Rocha } \\
\text { Monteiro }\end{array}$ & $\begin{array}{l}\text { Google } \\
\text { Acadêmico }\end{array}$ & 2013 \\
\hline $\begin{array}{l}\text { Reflexões, possibilidades e limitações } \\
\text { da atividade turística na comunidade } \\
\text { faxinalense de Taquari dos Ribeiros } \\
\text { de Rio Azul/ PR. }\end{array}$ & $\begin{array}{l}\text { Mariely de Andrade } \\
\text { Coelho }\end{array}$ & Google & 2016 \\
\hline $\begin{array}{l}\text { Possibilidades e adversidades frente } \\
\text { a inserção do turismo rural em pe- } \\
\text { quenas propriedades }\end{array}$ & $\begin{array}{l}\text { Elieti Fátima de } \\
\text { Goveia; Ronaldo } \\
\text { Ferreira Maganhotto; } \\
\text { Vanessa Alberton; } \\
\text { Leandro Baptista. }\end{array}$ & Google & 2017 \\
\hline
\end{tabular}

Fonte: Os autores (2018).

De posse dessas informações, estas foram analisadas e seus resultados transcritos de forma sintética, contribuindo, assim, para o cumprimento dos objetivos da presente pesquisa. 
Turismo rural em faxinais: uma alternativa não agrícola de desenvolvimento local e de fixação do homem no campo

\section{TURISMO RURAL}

O termo turismo rural, ainda está em formação, mas algumas definições expressam o que realmente deve ser entendido pela atividade. No Brasil, a EMBRATUR (apud SILVEIRA, 2001, p. 137) conceitua o Turismo com uma visão mercadológica considerando a atividade de turismo rural como "um conjunto de atividades turísticas comprometidas com a produção agropecuária, agregando valor ao produto do meio rural, resgatando e promovendo o patrimônio cultural e natural das comunidades do campo".

Mas existem autores que veem o turismo rural com uma ótica mais ligada aos aspectos culturais, como de Vaz (1999 apud SILVEIRA, 2001, p. 137), que coloca que o turismo rural diz respeito ao "conjunto de atividades que compõem a vida no campo, envolvendo a experiência do dia-a-dia nas fazendas, o convívio com camponeses, a montaria de pastagens, o sabor dos alimentos comidos diretamente da fonte, a existência de cavalos e plantações" (SILVEIRA, 2001, p. 137).

Conforme as Diretrizes para o Desenvolvimento do Turismo Rural, elaborado pelo Ministério do Turismo, entende-se Turismo no Espaço Rural como um recorte geográfico, onde o Turismo Rural está inserido. Isto é, as muitas práticas turísticas que ocorrem no espaço rural não são, necessariamente, Turismo Rural, e sim atividades de lazer, esportivas, ou ócio de citadinos, que ocorrem alheias ao meio em que estão inseridas. Isto é, considera-se Turismo no Espaço Rural ou em Áreas Rurais,

[...] todas as atividades praticadas no meio não urbano, que consiste de atividades de lazer no meio rural em várias modalidades definidas com base na oferta: turismo rural, agroturismo, turismo ecológico ou ecoturismo, turismo de aventura, turismo de negócios, turismo de saúde, turismo cultural, turismo esportivo, atividades estas que se complementam ou não. (GRAZIANO DA SILVA et al., 1998, p. 14).

Para Tulik (1997), se o turismo no meio rural for mal planejado e mal implementado, ele pode trazer mais malefícios que benefícios em decorrência dos impactos ambientais e sociais negativos que podem ser gerados. O setor público deve então se precaver, por meio de suas políticas, para não ser o responsável por problemas que poderão surgir em médio e longo prazos. 
O Brasil é um dos países com o maior potencial turístico do mundo, apesar de este ser pouco explorado. O território nacional tem mais de 8 milhões de quilômetros quadrados, fazendo divisa com 10 países e possuindo grande riqueza natural, representada por imensa costa marítima, rios, lagos, montanhas, fauna e flora que indicam a vocação para o turismo, em todas as suas formas (INSTITUTO BRASILEIRO DE TURISMO [EMBRATUR], 1994).

O turismo configura-se como um meio de desenvolvimento sustentável, responsável pela proteção tanto ambiental, quanto social e cultural. A obtenção de renda no interior dos municípios geralmente é agregada ao trabalho nas lavouras, renda esta obtida no período de safra.

O Turismo Rural pode ser apresentado como uma fonte extra de renda para a população territorializada em comunidades e que possuem pequenas glebas de terra, seja por meio de hospedagem, rotas turísticas e/ou comidas típicas.

Em meio à ruralidade, encontram-se comunidades com traços culturais acentuados, principalmente da imigração ucraniana, polonesa e alemã, que mantém sua religiosidade fervorosa, transmitindo de geração a geração seus costumes e crenças. Há de se destacar, portanto, o turismo religioso, com romarias e cavalgadas, preservando assim a tradição do sul do Brasil.

Analisar o potencial de desenvolvimento do Turismo Rural em áreas naturais torna-se relevante tanto para o crescimento das comunidades interioranas, quanto para o do município, que pode passar a receber maior número de turistas, movimentando sua economia.

Outro fator é apresentar para as comunidades que há outras formas de obtenção de renda, não sendo necessário um êxodo rural, fixando de certa maneira, o homem no campo, fortalecendo o associativismo comunitário, tanto no recebimento, quanto no atendimento ao turista consumidor.

Como consequência, pode-se obter melhoria da renda da população, uma maior valorização cultural, preservação ambiental, maior notoriedade, proporcionando assim, maior desenvolvimento comunitário. 
Turismo rural em faxinais: uma alternativa não agrícola de desenvolvimento local e de fixação do homem no campo

\section{SISTEMA FAXINAL}

Na virada do século passado, ocorreu a formação dos faxinais com as características apresentadas atualmente, mais especificadamente no período compreendido entre a decadência da pecuária e o fortalecimento da produção de erva-mate. Isso porque tanto os "fazendeiros dos campos nos tempos da atividade do criatório e do tropeirismo no século XVIII e $X I X$, quanto os caboclos nativos das matas mistas do Centro-Sul, tinham o costume de criar animais à solta" (OLIVEIRA, 2008).

Na década de 1980, foram realizadas muitas pesquisas sobre Faxinais, a maioria delas ligadas a economia, aspectos históricos, culturais e sociais, analisando o uso coletivo da terra, das áreas verdes e a criação de animais.

Os pioneiros no estudo dos Faxinais foram Carvalho e Chang, cuja abordagem consistia em seguir o ciclo de vida das comunidades, desde a criação e consolidação, até a desagregação, com foco nas variáveis econômicas. Tais autores tornaram-se referências fundamentais para os pesquisadores posteriormente (SOLIS CAMPOS; GONZAGA, 2015), como Carvalho (1984), que realizou uma abordagem diferenciada sobre os Faxinais, ao apresentar as peculiaridades deste modo de criadouro comunitário- forma de organização entre os proprietários da terra para o seu uso comum na criação de animais. Segundo Oliveira (2008, p. 43-4)

[...] constitui uma experiência de desenvolvimento sustentável de grande importância ecológica e histórica da região, constituindo parte significativa da cobertura florestal remanescente do estado. Trata-se de uma forma de produção camponesa tradicional da região Centro Sul do Paraná que tem como traço marcante o uso coletivo da terra conciliado a atividades de subsistência familiar com atividades agrossilvopastoril e conservação ambiental, incluindo a proteção das 30 espécies que, juntamente com a erva-mate, caracterizam a vegetação local.

O modo de uso da terra nesse sistema pode ser dividido em dois espaços, o espaço de uso comum, onde os animais são criados soltos, e as áreas de uso particular, onde se desenvolvem atividades agrícolas, geralmente essas áreas são separadas por cercas ou valas (MUDREI, 2011). 
Talvez os maiores problemas encontrados nos faxinais encontrem-se nas divergências existentes nesse sistema, principalmente entre os próprios moradores, o que pode acarretar na dissolução desses espaços, sem contar no uso exacerbado dos bens comuns.

Hardin (1968), em seu artigo intitulado "A tragédia dos Comuns", alertava sobre o destino trágico dos recursos comuns nas mãos da humanidade e, como ele mesmo aponta, é um problema sem solução técnica; porém, três décadas depois, seu trabalho foi questionado por Ostrom, que em 1999 publicou um artigo intitulado "Revisitando os comuns: lições locais, desafios globais", no qual afirma que comunidades tradicionais conseguem resolver seus conflitos sozinhos e sem a intervenção de forças estatais e/ou a necessidade da privatização, conforme previa Hardin (1968).

De acordo com Chang (1988), o Sistema Faxinal constitui-se numa forma histórica de organização social e produção que mais preservou as condições ambientais, comparada a outras formas organizacionais da produção; porém áreas que ainda mantêm esse sistema de vida agropastoril enfrentam um grande êxodo rural, decorrente na maioria das vezes, da falta de políticas públicas, tanto municipais quanto estaduais, dirigidas às comunidades para a fixação do homem no campo.

Em julho de 2004, criou-se a "Rede Faxinal", que envolve representantes de órgãos governamentais, instituições de ensino/pesquisa, prefeituras municipais e comunidades faxinalenses atuando na defesa e promoção das terras e povos de Faxinal com o intuito de buscar alternativas sustentáveis de renda para tais comunidades.

Até a metade do século XX, um quinto do território paranaense era composto pelos Faxinais, que se formaram, sobretudo, nas áreas onde se encontravam as Florestas de Araucárias. O levantamento mais abrangente, realizado até o momento, foi o da Empresa Paranaense de Assistência Técnica e Extensão Rural (EMATER) em 1994. Segundo esse levantamento, o número total de Faxinais, no Paraná, chegava a 121. Uma atualização de 2004, efetuada pelo Instituto Ambiental do Paraná (IAP), demonstra que 44 destes ainda se mantinham, agregando então aproximadamente 3.000 famílias, com uma população estimada em 16.000 habitantes. 
Turismo rural em faxinais: uma alternativa não agrícola de desenvolvimento local e de fixação do homem no campo

Em 2008, um novo levantamento feito pelo Mapeamento Social Faxinais, apontou a existência de 227 (duzentos e vinte e sete) faxinais em território paranaense, distribuídos em microrregiões geográficas conforme o quadro a seguir.

Quadro 2- Posição dos faxinais pelas microrregiões geográficas

\begin{tabular}{|l|l|l|c|}
\hline \multicolumn{1}{|c|}{ Mesorregião } & \multicolumn{1}{|c|}{ Microrregião } & \multicolumn{1}{c|}{ Município } & $\begin{array}{c}\text { N. de } \\
\text { Faxinais }\end{array}$ \\
\hline Metropolitana Curitiba & Curitba & Mandirituba & 15 \\
\hline Metropolitana Curitiba & Rio Negro & Quitandinha & 13 \\
\hline Metropolitana Curitiba & Rio Negro & Tijucas do Sul & 9 \\
\hline Metropolitana Curitiba & Rio Negro & Agudos do Sul & 6 \\
\hline Metropolitana Curitiba & Rio Negro & Piên & 4 \\
\hline Metropolitana Curitiba & Lapa & Lapa & 16 \\
\hline Sudeste & Prudentópolis & Prudentópolis & 14 \\
\hline Sudeste & Prudentópolis & Imbituva & 8 \\
\hline Sudeste & Prudentópolis & Fernandes Pinheiro & 5 \\
\hline Sudeste & Prudentópolis & Teixeira Soares & 1 \\
\hline Sudeste & Irati & Rio Azul & 7 \\
\hline Sudeste & Irati & Irati & 14 \\
\hline Sudeste & Irati & Rebouças & 15 \\
\hline Sudeste & Irati & Mallet & 1 \\
\hline Sudeste & São Mateus do Sul & São Mateus do Sul & 4 \\
\hline Sudeste & São Mateus do Sul & São João do Triunfo & 16 \\
\hline Sudeste & São Mateus do Sul & Antonio Olinto & 1 \\
\hline Centro-Oriental & Ponta Grossa & Palmeira & 9 \\
\hline Centro-Oriental & Ponta Grossa & Ponta Grossa & 1 \\
\hline Centro-Oriental & Telêmaco Borba & Imbaú & 4 \\
\hline Centro-Oriental & Telêmaco Borba & Reserva & 17 \\
\hline Centro-Sul & Guarapuava & Inácio Martins & 13 \\
\hline Centro-Sul & Guarapuava & Pinhão & 4 \\
\hline Centro-Sul & Guarapuava & Reserva do Iguaçu & 1 \\
\hline Centro-Sul & Guarapuava & Turvo & \\
\hline Centro-Sul & Guarapuava & Guarapuava & 13 \\
\hline Centro-Sul & Guarapuava & Campina do Simão & \\
\hline & & & 17 \\
\hline
\end{tabular}




\begin{tabular}{|l|l|l|c|}
\hline \multicolumn{1}{|c|}{ Mesorregião } & \multicolumn{1}{|c|}{ Microrregião } & \multicolumn{1}{c|}{ Município } & $\begin{array}{c}\text { N. de } \\
\text { Faxinais }\end{array}$ \\
\hline Centro-Sul & Guarapuava & Guaraniaçu & 1 \\
\hline Centro-Sul & Guarapuava & Nova Laranjeiras & 1 \\
\hline Centro-Sul & Pitanga & Pitanga & 3 \\
\hline Centro-Sul & Pitanga & Mato Rico & 1 \\
\hline Centro-Sul & Pitanga & Boa Ventura de São Roque & 2 \\
\hline Total & & & $\mathbf{2 2 7}$ \\
\hline
\end{tabular}

Fonte: Adaptado de Pesquisa Mapeamento Social Faxinais (2008).

Conforme apresentado no Quadro 2, a microrregião com predominância no número de faxinais é a de Guarapuava (55), com destaque para os municípios de Inácio Martins (17), Pinhão (15) e Turvo (13), seguido pela microrregião de Irati, com um total de 37 faxinais, sendo 15 deles situados no município de Rebouças.

Sob a égide social, os faxinais permitem uma vivência com baixa aplicação de recursos e mão de obra, em que os pequenos produtores assim se viabilizam, a produção permanece calcada em atividades agrícolas e pecuárias.

Assim sendo, a implantação de projetos de turismo rural como fator de desenvolvimento local e econômico pode surtir efeito na minimização do êxodo que ocorre, desde que sigam os quatro princípios elencados por Bravo (2000): "deve ser economicamente viável; ecologicamente correto; socialmente justo; e verdadeiramente rural", visando à preservação das áreas naturais.

\section{RESULTADOS E DISCUSSÕES}

Todos os estados brasileiros apresentam potenciais turísticos distintos, o estado do Paraná, por exemplo, apresenta dentre os atrativos, práticas turísticas desenvolvidas em ambientes naturais como o turismo rural- atividade relativamente nova que vem se desenvolvendo no Brasil ao longo das últimas décadas.

Dentre os espaços rurais paranaenses, ainda se encontram comunidades tradicionais que preservam seus modos de vivência. As comunidades 
Turismo rural em faxinais: uma alternativa não agrícola de desenvolvimento local e de fixação do homem no campo

faxinalenses, apesar de todas as resistências existentes em manter essa cultura de criação de animais em áreas comunais, têm encontrado dificuldades para manter a população no campo, devido à falta de atividades rentáveis que superem as dificuldades apresentadas pela agricultura.

Nesse sentido, atividades não agrícolas como o turismo rural podem ser apresentadas como fonte de renda extra e fixação do homem no campo. As pesquisas nessa área ainda são tímidas. Destacam-se, porém, alguns estudos que corroboram com a temática: Turismo rural em faxinais.

Silva (2012) fez o diagnóstico da potencialidade turística da propriedade Faxinal Dérevo, na comunidade Papanduva de Baixo do município de Prudentópolis, PR, concluindo que mesmo a propriedade possuindo potencial turístico como o faxinal, a gastronomia, as tradições, museu, trilhas e produtos artesanais, este ainda não é tido como fonte de renda para a família, pois a demanda de turistas é muito insignificante, ocasionada principalmente pela falta de infraestrutura básica como sinalização e placas de acesso apontada como responsabilidade do município.

Monteiro (2010), por sua vez, fez uma reflexão sobre a proposta de turismo em dois faxinais do município de Mallet, concluindo que o turismo nos Faxinais pode se caracterizar como alternativa aos produtores faxinalenses que podem garantir outras fontes de renda que não exclusivamente a agricultura, bem como a valorização de suas tradições, culturas e modo de vida, com vistas à sustentabilidade.

Outra autora que corrobora com essa temática é Oliveira (2008), que faz um levantamento dos faxinais existentes no município de Prudentópolis, apresentando as potencialidades e perspectivas para o turismo rural. A autora conclui que a atividade turística na região surge como alternativa para impulsionar o desenvolvimento dos faxinais de Taboãozinho e Barra Bonita, evidenciando a importância do turismo rural para o desenvolvimento dessas comunidades faxinalenses, através do resgate e promoção do patrimônio cultural (festas religiosas, mutirões, artesanatos e outras comemorações) e natural (rios, serras, cachoeiras, vegetação entre outros), em contrapartida apresenta a necessidade de implementação de medidas efetivas através de órgão públicos para subsidiar as atividades referentes ao Turismo Rural, bem 
como efetivo monitoramento para minimizar nas comunidades os impactos negativos promovidos pelo turismo.

Seguindo a mesma linha de pesquisa de Oliveira, outro trabalho acerca da temática e no mesmo município paranaense, foi o desenvolvido por Lemes (2010), apresentando o Turismo comunitário e a importância em se buscar a opinião da comunidade em relação à prática da atividade turística em seu meio, evitando possíveis conflitos e choques de cultura. Aborda também a necessidade na identificação do interesse dessas comunidades bem como o preparo para a recepção dos turistas.

Com o intuito de discutir as possibilidades e desafios para implementação do turismo em áreas de comunidades tradicionais, especialmente o caso do município de Mallet, PR, bem como a maneira como esse plano contempla as comunidades faxinalenses e as implicações do turismo nessas áreas, Monteiro (2013) apresenta a questão do desenvolvimento de um projeto de roteiro turístico num circuito Polonês-Ucraniano, incorporando o Faxinal Lageado de Baixo com vistas a possibilitar maior contato entre turista e patrimônio cultural dos imigrantes e, também, com o patrimônio ambiental das comunidades faxinalenses, porém o autor alerta sobre a dificuldade da inserção do turismo em comunidades tradicionais sem causar impactos ambientais como a degradação da Mata de Araucárias, ao modo de vida e ao patrimônio cultural das comunidades.

Coelho (2016) se propôs a investigar se a atividade turística pode figurar como alternativa de renda para a comunidade faxinalense Taquari dos Ribeiros, localizada no município de Rio Azul, PR, concluindo que o turismo pode gerar benefícios socioeconômicos significativos, ao contribuir para a melhora das condições de vida da população local, geração de renda complementar, aumento do envolvimento da comunidade, minimização do êxodo rural, e propiciando o resgate das manifestações culturais, através de ações e projetos futuros estruturados pelo poder público local, com o auxílio de profissionais especializados e com o envolvimento direto da comunidade. A autora conclui que a atividade turística nessa comunidade faxinalense não obtém êxito devido a algumas limitações, como as más condições de acesso, a deficiência na infraestrutura básica, a falta de recursos para investimentos em projetos voltados ao turismo, de profissionais especializados e de en- 
Turismo rural em faxinais: uma alternativa não agrícola de desenvolvimento local e de fixação do homem no campo

volvimento da comunidade, além do abandono das atividades tradicionais pela população local. Tais fatores apresentam-se como empecilhos para o desenvolvimento do turismo na região.

\section{CONSIDERAÇÕES FINAIS}

Procurar alternativas que garantam a sobrevivência dos faxinais que ainda restam no interior dos municípios paranaenses, bem como técnicas para a diminuição do êxodo rural é de fundamental importância tanto para a preservação do ecossistema, como para o modo de vida, da cultura e das identidades dessas comunidades tradicionais.

A falta de políticas públicas que proporcionem a permanência do pequeno proprietário em suas terras faz com que os pequenos produtores vendam suas glebas para grandes monocultores e procurem novas condições de vida nas cidades.

O Sistema Faxinal deve ser analisado não apenas como um dado geográfico; faz-se necessário conhecer a peculiaridade de seus moradores, bem como suas culturas, costumes e tradições, resultante de um processo histórico, formado por elementos humanos e naturais que necessitam de preservação.

Em conclusão, nas últimas décadas os territórios pertencentes aos faxinais estão perdendo espaço para o agronegócio através da monocultura. Buscando fazer frente a essa realidade e assegurar suas pequenas glebas de terra, sua cultura e seu modo de vida, os povos faxinalenses necessitam de apoio para o desenvolvimento de novas atividades e práticas não agrícolas, capazes de superar a agricultura e garantir renda extra às famílias.

A procura por atividades não agrícolas fez ascender a questão do turismo rural como fonte de renda extra e desenvolvimento comunitário para as comunidades tradicionais, haja vista que a bibliografia sobre turismo em áreas rurais no Brasil ainda apresenta certa restrição, sendo maior parte dela responsável pela apresentação de estudos de casos em andamento, bem como pela exaltação dos benefícios gerais da atividade e a divulgação do processo de planejamento do ecoturismo na região. Ao nível estadual, as pesquisas voltam-se para estudos de caso, direcionados principalmente para o município de Prudentópolis/PR, que possui em seus domínios 14 faxinais, 
que representam 6,17\% de todos os faxinais encontrados em território paranaense, mesmo número inclusive que os levantados no município de Irati.

Conforme levantamento, alguns estudos foram desenvolvidos na área do turismo faxinalense no estado do Paraná. Muitos deles apontam as limitações encontradas para o desenvolvimento da atividade turística, entre as quais se destacam as más condições de acesso, a deficiência na infraestrutura básica, a falta de recursos para investimentos em projetos voltados ao turismo, de profissionais especializados e de envolvimento da comunidade, o abandono das atividades tradicionais pela população local e a falta de políticas públicas de incentivo voltadas para a criação de projetos turísticos e sua divulgação.

Por isso, consideramos que é fundamental que se produzam estudos e publicações que contribuam para o conhecimento de novas comunidades faxinalenses que possuem atrativos turísticos, auxiliando na organização comunitária, em seu desenvolvimento e no combate ao êxodo rural.

\section{REFERÊNCIAS}

BRAVO, Renato. Turismo rural, esse desconhecido. Estudos Turísticos. 2000. Disponível em: http://bdm.unb.br/bitstream/10483/239/3/2003_ TharsoPadilhaNogueira.pdf. Acesso em: 8 jun. 2017.

CARVALHO, Horácio M. de. Da aventura à esperança: a experiência auto-gestionária no uso comum da terra. Curitiba, PR, 1984. (mimeografado).

CHANG, Man Yu Sistema faxinal: uma forma de organização camponesa em desagregação no Centro-Sul do Paraná. Londrina, PR: IAPAR, 1988. (Boletim Técnico, 22, 121f.).

COELHO, Mariely de Andrade. Reflexões, possibilidades e limitações da atividade turística na comunidade faxinalense de Taquari dos Ribeiros de Rio Azul/PR. 2016. 59f. Monografia (Trabalho de Conclusão de Curso de Turismo) - Universidade Estadual do Centro-Oeste (UNICENTRO), Irati, PR, 2016.

ELSEVIER. Scopus. Material publicitário. Amsterdam, 2010.

GOVEIA, Elieti Fátima de; MAGANHOTTO, Ronaldo Ferreira; ALBERTON, Vanessa; BAPTISTA, Leandro. Possibilidades e adversidades frente a inserção do turismo 
Turismo rural em faxinais: uma alternativa não agrícola de desenvolvimento local e de fixação do homem no campo

rural em pequenas propriedades. Revista Espacios, v. 38, n. 51, 2017. Disponível em: https://www.revistaespacios.com/a17v38n51/a17v38n51p16.pdf. Acesso em: 12 jun. 2017.

GRAZIANO DA SILVA, José et al. Turismo em áreas rurais: suas possibilidades e limitações no Brasil. In: ALMEIDA, J. A. et al. (Org.). Turismo rural e desenvolvimento sustentável. Santa Maria, RS: Centro Gráfico, 1998.

HARDIN, Garrett. The tragedy of the commons. Science, v. 162, n. 3859, p. 1243-8, dez. 1968. Disponível em: https://science.sciencemag.org/content/162/3859/1243. Acesso em: 21 dez. 2014

INSTITUTO BRASILEIRO DE TURISMO (EMBRATUR). Manual do turismo rural. Brasília: Ministério da Indústria, do Comércio e do Turismo, 1994.

LEMES, Pedro Henrique Sanches. Turismo comunitário: reflexões sobre os faxinais do município de Prudentópolis - Paraná. UNOPAR Científica, Revista de Educação e Ciências Humanas, Londrina, PR, v. 11, n. 1, p. 51-8, jun. 2010.

MONTEIRO, Rodrigo Rocha. O turismo em comunidades tradicionais faxinalenses: uma discussão sobre as transformações recentes no campo brasileiro e seus reflexos para as comunidades tradicionais. Revista Pegada, Presidente Prudente, SP, v. 14, n. 2, p. 177-93, dez. 2013.

MONTEIRO, Rodrigo Rocha. O novo rural em comunidades tradicionais faxinalenses: reflexões sobre a proposta de turismo para os faxinais do município de Mallet Paraná - Brasil. Revista Geográfica de América Central, Costa Rica, Número Especial EGAL, p. 1-15, II sem. 2010.

MUDREI, Taciana Aparecida. Turismo rural: valorização da cultura ucraniana. Prudentópolis, PR: CEDEJOR- Centro de Desenvolvimento do Jovem Rural. 2011. 22 p. Projeto do Jovem Empreendedor Rural - PJER.

OLIVEIRA, Dircéia Antunes de. Os faxinais do município de Prudentópolis-PR: potencialidade e perspectivas para o turismo rural. 2008. Dissertação (Mestrado em Turismo e Hotelaria) - Universidade do Vale do Itajaí (UNIVALI), Balneário Camboriú, SC, 2008.

OSTROM, Elinor et al. Revisiting the commons: local lessons, global challenges. Science, v. 284, n. 5412, p.278-82, abr. 1999. 
PRICE, Derek J. de Solla. O desenvolvimento da ciência: análise histórica, filosófica, sociológica e econômica. Rio de Janeiro: Livros Técnicos e Científicos, 1976.

SILVA, Mozart Martins. Diagnóstico da potencialidade turística da propriedade Faxinal Dérevo, na Comunidade Papanduva de Baixo do Município de Prudentópolis/ PR. 2012. 59f. Monografia (Trabalho de Conclusão de Curso de Turismo) Universidade Estadual do Centro-Oeste (UNICENTRO), Irati, PR, 2012.

SILVEIRA, Marcos T. Política de turismo: oportunidades ao desenvolvimento local. In: RODRIGUES, Adyr B. (Org.). Turismo rural: práticas e perspectivas. São Paulo: Contexto, 2001. p. 133-50.

SOLIS CAMPOS, Roger Alexis; GONZAGA, Carlos Alberto Marçal. Os faxinais do Paraná: uma revisão teórica e um estudo sobre sua mobilização social. In: CONINTER - CONGRESSO INTERNACIONAL INTERDISCIPLINAR EM SOCIAIS E HUMANIDADES, 4., 2015, Foz do Iguaçu, PR. Disponível em: https://www.academia.edu/20828546/ OS_FAXINAIS_DO_PARAN\%C3\%81_UMA_REVIS\%C3\%830_TE\%C3\%93RICA_E_ UM_ESTUDO_SOBRE_SUA_MOBILIZA\%C3\%87\%C3\%830_SOCIAL

TULIK, Olga. Do conceito às estratégias para o desenvolvimento do turismo rural. In: RODRIGUES, Adyr (Org.). Turismo e desenvolvimento local. São Paulo: Hucitec, 1997. p. 136-43. 